\title{
Percutaneous Dilatational Tracheostomy
}

\author{
So Yun Lim, Kwi Ju Yu, Seulah Lee, and Inn Chul Nam \\ Department of Otolaryngology-Head and Neck Surgery, Incheon St. Mary's Hospital, College of Medicine, \\ The Catholic University of Korea, Seoul, Korea
}

\author{
경피적 확장 기관절개술 \\ 임소연 · 유귀주 · 이슬아 · 남인철 \\ 가톨릭대학교 의과대학 인천성모병원 이비인후과학교실
}

\author{
Received October 10, 2021 \\ Revised November 9, 2021 \\ Accepted November 23, 2021 \\ Address for correspondence \\ Inn Chul Nam, MD, PhD \\ Department of Otolaryngology- \\ Head and Neck Surgery, \\ Incheon St. Mary's Hospital, \\ College of Medicine, \\ The Catholic University of Korea, \\ 56 Dongsu-ro, Bupyeong-gu, \\ Incheon 21431, Korea \\ Tel +82-32-280-5843 \\ Fax +82-32-280-5157 \\ E-mail entnam@catholic.ac.kr
}

\begin{abstract}
Percutaneous dilatational tracheostomy (PDT) is an increasingly popular method with several advantages, such as being able to perform at bedside with a simple kit, with a less number of medical staff and less amount of time. PDT is easier to perform, offers less bleeding risks and post-operative infection rates compared to conventional surgical tracheotomy. However, PDT is being performed more in the pulmonology and intensive care medicine than in otolaryngology. Herein, we introduce PDT and share our experiences, hoping otolaryngologists use our procedure more.

Korean J Otorhinolaryngol-Head Neck Surg 2022;65(2):121-4
\end{abstract}

\section{서 론}

경피적 확장 기관절개술(percutaneous dilatational tracheostomy)은 1985년 Ciaglia 등에 의해 처음 소개된 술식 으로, 기존의 관혈적 기관절개술과는 다르게 절개하여 기관 을 노출시키지 않고 기관 절개 튜브를 삽입할 수 있는 술식으 로, 침상 곁에서(bedside) 곧바로 시행할 수 있어 환자를 이송 하는 데 따르는 위험을 줄일 수 있고, 수술장을 이용하지 않 고 적은 인원으로 시행할 수 있어 경비가 절감되며, 시술 방 법을 배우기 쉬운 장점이 있다.23) 이러한 장점으로 인해 그 시행 빈도가 점차 증가하고 있으며, 보고에 따르면 중환자실 환자에게 시행하는 기관절개술의 경우 경피적 확장 기관절개 술이 기존의 관혈적 기관절개술을 대체한다는 연구 결과도

This is an Open Access article distributed under the terms of the Creative Commons Attribution Non-Commercial License (https://creativecommons.org/licenses/by-nc/4.0) which permits unrestricted non-commercial use, distribution, and reproduction in any medium, provided the original work is properly cited.
보고된 바 있다. ${ }^{4}$

경피적 확장 기관절개술은 기구가 세트(set)의 형태로 사용 하기 편하게 구비되어 있으며, 짧은 시간 안에 쉽게 시행할 수 있고 덜 침습적이기 때문에 침상 곁에서 시행하기에 관혈적 기관절개술에 비해 훨씬 편하다고 할 수 있다. 두 시술법을 비교한 메타분석에 따르면, 경피적 확장 기관절개술은 쉽게 시행할 수 있고, 출혈이 적으며, 시술 후 감염이 적은 장점이 있다. ${ }^{5)}$ 이러한 장점으로 인해 국내에서도 2009년 신의료기술 로 인정받은 이후로 사용 빈도가 점차 증가하고 있다. 하지만 이비인후과에서 본 시술을 시행하는 경우는 많지 않으며, 중 환자실 환자에게 기관절개술을 시행할 때 호흡기내과나 중환 자의학 분야에서 직접 경피적 확장 기관절개술을 시행하여 이비인후과에 기관절개술을 의뢰하는 빈도가 점차 줄어들고 있는 실정이다.

기관절개술을 전문적으로 시행하는 이비인후과 의사로서 기관절개술에서의 주도권을 잃지 않고 전문성을 유지하기 위 
해 새로운 술법을 알고 익혀 시행할 줄 알아야 한다. 본 논문 의 목적은 경피적 확장 기관절개술을 소개하고 시술 방법을 설명하여 이비인후과에서도 경피적 확장 기관절개술을 활발 히 시행하도록 하기 위함이다.

\section{방 법}

\section{환자 선택}

본 시술의 일반적인 적응증과 금기는 관혈적 기관절개술과 크게 다르지 않다. 환자 선택은 생리학적, 해부학적 관점에서 판단한다. 환자의 상태가 안정되어야 하고, 적절한 산소 공급 이 이루어지고 있어야 하며, 출혈경향이 없어야 한다. 일반적 으로는 기관 삽관이 이루어진 환자를 대상으로 하며, 그렇지 않은 경우에는 상대적 금기로 되어있다.6) 본 시술은 기관을 직접 노출하여 확인하지 않고 기관 천자를 통해 기관절개를 시행하기 때문에 갑상연골 및 윤상연골, 흥골절흔(sternal notch) 등 전경부의 해부학적 지표(anatomic landmark)가 잘 확인되는 환자를 대상으로 해야 한다. 또한 윤상연골과 흥골절흔 사이의 간격이 최소한 3-4 cm 정도로 충분해야 기 관에 정확하게 천자할 수 있다. 따라서 목이 짧거나 굵은 환 자, 이전의 갑상선 수술 등 경부 수술로 인해 해부학적 지표 가 잘 확인되지 않는 환자에서는 시행하지 않는 것이 좋다. 이 외에도 천자할 위치에 종괴가 있거나, 갑상선 종괴나 비대 가 있는 경우 시행이 어렵다. 또한 15 세 이하의 소아는 기관 이 작고 잘 움직여 정확한 기관 천자가 어렵고, 기관연골의 지지력이 약해 확장 과정에서 기관 내강의 붕괴(collapse)가 일어날 수 있어 절대 금기로 알려져 있다. ${ }^{7)}$

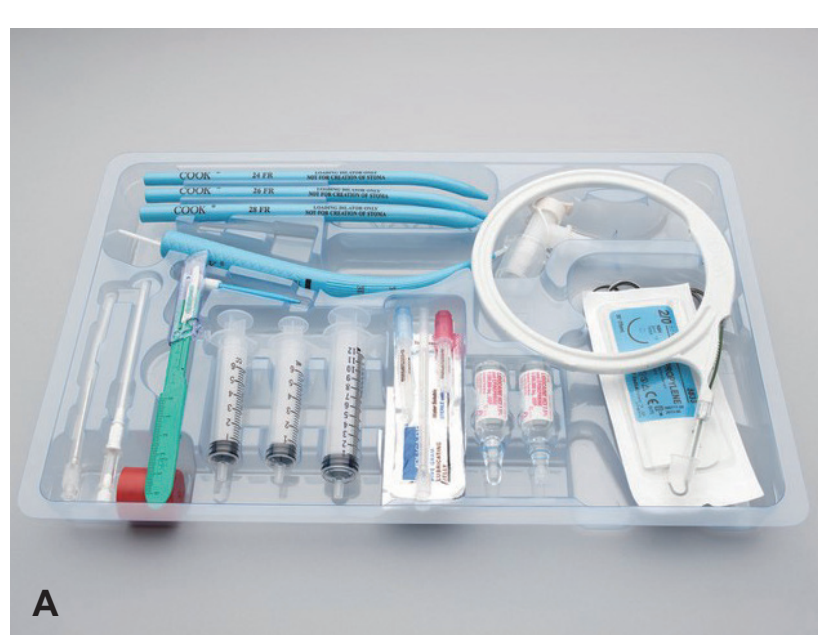

\section{시술 방법}

경피적 확장 기관절개술의 방법은 현재까지 Ciaglia method, Grigg method, Fantoni method, Percu-Twist method 등 다양한 방법이 소개되어 있다. ${ }^{8-10)}$ 그 중에서 기관 절개 후 확장술을 이용한 Ciaglia method가 가장 많이 사용되고 있 어 본 논문에서는 이 방법을 설명하겠다.

환자의 자세는 관혈적 기관절개술과 같다. 환자는 앙와위 로 두고 어깨 밑에 베개를 받쳐 목을 신전시킨다. 본 시술은 원칙적으로 기관 삽관이 되어 있는 환자를 대상으로 하므로, 시술 전에 기관 삽관 튜브를 약간 빼서 튜브 끝이 성대 바로 아래에 위치하도록 하여 기관 천자 시 튜브가 방해하지 않도 록 한다. 시술이 실패할 경우 다시 기관 삽관을 해야하기 때문 에 기관 삽관 튜브는 완전히 제거하지 않는 것이 좋다. 시술은 보통 상품화된 세트(Ciaglia Blue Rhino Percutaneous Dilatational Tracheostomy Kit ${ }^{\circledR}$, Cook Critical Care, Bloomington, IN, USA)를 사용하여 시행한다(Fig. 1). 세트는 국 소마취제, 주사기, 기관 천자용 바늘, 칼, introducer dilator, gradual dilator, tube loading dilator, 유도 철심, 봉합사 등 으로 구성된다. 세트 내에 포함된 칼을 이용하여 약간의 피부 절개를 내고, $18 \mathrm{G}$ 바늘이 달린 주사기에 생리식염수를 넣고 기관 정중앙부를 천자한다. 바늘이 기관을 천자한 느낌이 있 으면 주사기를 역류시켜 공기가 천자됨을 통해 기관 천자가 이루어짐을 확인한다. 바늘만 남겨놓고 주사기를 제거한 후 바늘을 통해 기관 내로 유도 철심(guide wire)을 삽입한다. 유도 철심이 충분히 기관 내로 들어가면, 바늘을 제거하여 유도 철심만을 남겨놓은 뒤 확장을 시작한다. 첫 확장은 introducer dilator를 유도 철심을 따라 삽입하여 시행하고, 다 음으로 gradual dilator를 삽입하여 기관 천자 창을 충분히 확장한다. 유도 철심은 그대로 둔 채 gradual dilator를 제거

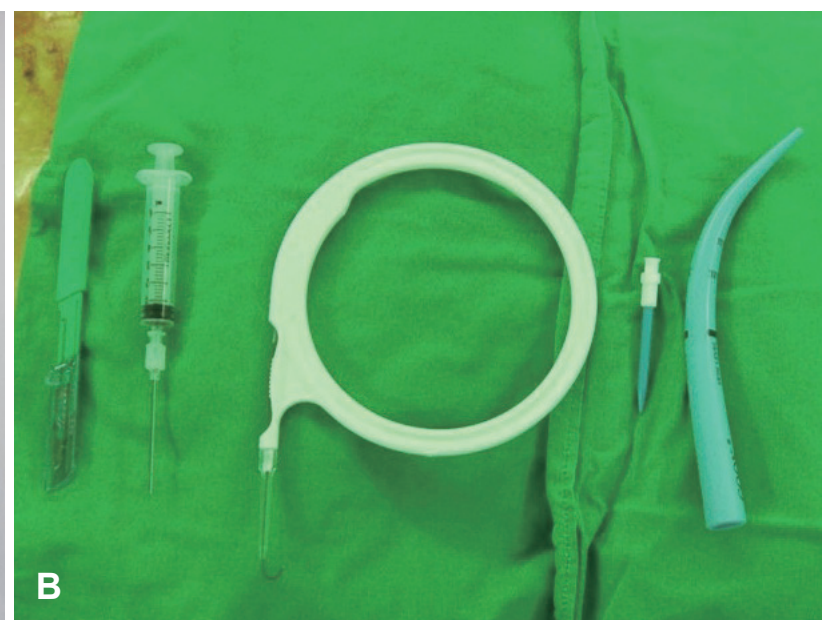

Fig. 1. Instruments needed for the procedure. A: Ciaglia Blue Rhino Percutaneous Dilatational Tracheostomy Kit ${ }^{\circledR}$. B: Instruments from the kit actually used during the procedure: knife, syringe with needle, guidewire, introducer dilator, gradual dilator (from left to right). 
한 후 유도 철심을 따라 기관 절개 튜브를 삽입한다. 제작사 에 따라 튜브에 유도 철심을 넣을 수 없는 튜브도 있으므로 시술 시행 전에 미리 확인이 필요하다. 저자는 튜브 내에 유도 철심을 넣을 수 있도록 제작된 $\mathrm{TRACOE}{ }^{\circledR}$ 제품을 사용하고 있다. 유도 철심을 넣을 수 없는 튜브를 사용할 경우 세트에 포함되어 있는 loading dilator를 튜브의 내관에 삽입한 후 여 기에 유도 철심을 넣어 사용한다. 튜브가 기관 내로 잘 삽입됨 을 확인하면 기관 삽관 튜브를 제거하고 시술을 마친다(Video 1). 관혈적 기관절개술과는 다르게 최소한의 피부절개를 하고 광경근막하 박리(subplatysmal dissection)의 과정을 생략하 기 때문에 시술 후 지혈과 피하기종의 발생을 예방하기 위한 상처부위 거즈 패킹이나 절개부위 봉합을 할 필요가 없어 상 처부위가 훨씬 더 깔끔하다(Fig. 2).

기관 천자 시 정확한 위치에의 천자를 위해 기관 삽관 튜브 를 통하여 굴곡형 후두경이나 기관지경을 넣어 직접 확인하 는 방법도 있고, 초음파를 이용하여 기관 정중앙의 정확한 천 자부위를 찾는 방법도 있다. ${ }^{6,11}$ 경험이 많지 않을 때는 후두 경이나 기관지경으로 정확한 천자 위치 확인 및 유도 철심과 확장기 및 기관 절개 관이 정확하게 삽입되는지 확인하는 것 이 합병증의 발생이나 시술 실패를 피하는 데 도움이 된다. 숙 련이 되면 내시경이나 초음파의 도움 없이도 적절한 위치에 기관 천자를 시행하고 시술을 안전하게 시행할 수 있다.

\section{관혈적 기관절개술과의 비교}

저자들은 경피적 확장 기관절개술의 유용성을 알아보기 위해 중환자실 환자에게 침상 곁에서 시행하는 기관절개술 시 경피적 확장 기관절개술과 관혈적 기관절개술을 시행하 여 비교하는 연구를 진행하였다. 총 43명의 환자를 대상으로 29 명에게 경피적 확장 기관절개술을, 14 명에서 관혈적 기관

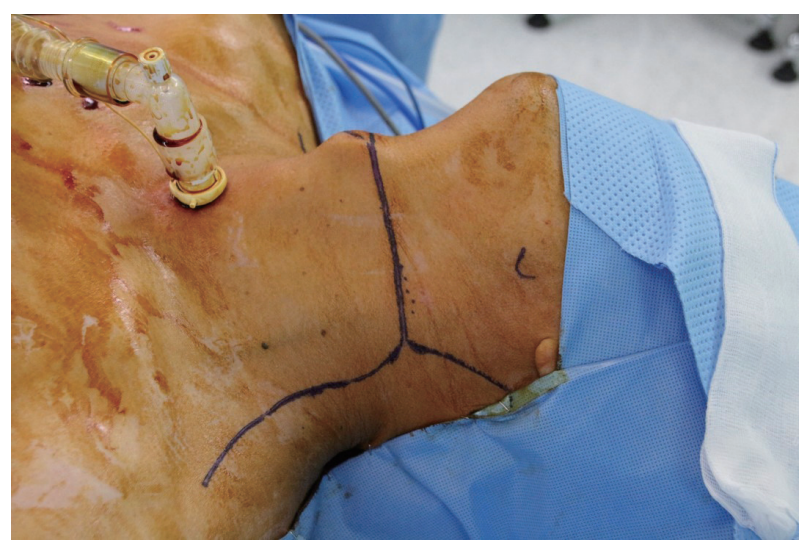

Fig. 2. Post-PDT state. In this case, PDT was performed as the tracheostomy before head and neck cancer surgery. The tube flange was removed to secure better surgical field. It is kept clean without open wound around the tube. PDT, percutaneous dilatational tracheostomy.
절개술을 시행하여 비교하였고, 경피적 확장 기관절개술이 출혈량이 적었고 시술 시간이 평균 8.0 분으로 관혈적 기관절 개술의 21.6분보다 유의하게 짧았다. 합병증 발생률은 두 시 술 간에 유의한 차이를 보이지 않았다. ${ }^{12)}$

\section{합병증}

경피적 확장 기관절개술과 관혈적 기관절개술의 합병증을 비교한 메타분석에 따르면, 두 시술 간에 전체적인 합병증의 빈도는 비슷하거나 경피적 확장 기관절개술이 약간 낮은 것 으로 알려져 있다. ${ }^{5,13)}$ 관혈적 기관절개술과 마찬가지로 합병 증은 초기 합병증과 후기 합병증으로 나눌 수 있다. ${ }^{14)}$ 보고자 에 따라 차이가 있지만 합병증의 빈도는 $4.1 \%$ 에서 $12 \%$ 정도 로 보고되며, 대부분의 합병증은 미미하다. 초기 합병증에는 유도철심이나 기관절개관의 잘못된 통로로의 삽입, 시술의 실패, 기관연골 골절, 출혈, 기흥, 피하기종 등이 있으며, 후기 합병증에는 기관절개공 주변의 감염 및 농형성, 종격동염, 기 관협착, 기관-무명동맥루, 기관-식도루 등이 있다. ${ }^{15,16)}$ 초기 합병증의 대부분은 시술에 익숙해지면 발생빈도를 줄일 수 있다. 초기 합병증 중 기관주위 공간으로의 삽관은 경피적 확 장 기관절개술 특이 합병증으로 그 빈도는 약 $1 \%$ 로 알려져 있다. 이는 시술 초기에 정확한 위치로의 기관 천자가 이루어 지지 않은 경우 확장기로 기관 전벽을 확장시키는 과정에서 유도철사가 휘면서 확장기가 기관주위 공간으로 잘못 삽입되 어 발생할 수 있다. 저자들도 시술 초기에 기관주위 공간으로 잘못 삽입한 후 과도한 환기를 시행하여 기흥, 종격동기종, 기복증이 한꺼번에 발생한 합병증을 경험한 바가 있다. ${ }^{17)}$ 따 라서 기관 천자 시 기관 전벽의 정중앙에 정확하게 시행하는 것이 본 합병증을 예방하는 데 중요하다. ${ }^{2,4)}$ 기관-식도루의 경우 기관 천자 시 기관 후벽에 손상을 주는 경우에 발생할 수 있으며, 주사기로 기관 천자 후 주사기를 역류하여 공기가 나오는 것을 확인하거나 천자 시 후두경이나 기관지경을 통 해 직접 확인하며 시행하면 피할 수 있다.

시술 중 여러가지 이유로 시술 자체를 실패하는 경우가 간 혹 발생할 수 있으며, 이 경우 관혈적 기관절개술로의 전환이 필요하다. 이 점이 본 시술을 이비인후과 의사가 시술할 때의 장점이라고 할 수 있다. 이 외에도 타과에서 시행할 경우 굴 곡형 기관지경으로 반드시 확인하며 시행하기 때문에 추가적 인 인력과 비용이 필요한 반면, 이비인후과 의사의 경우 후 두 및 기관의 해부학적 구조에 익숙하기 때문에 충분히 숙달 되면 이러한 내시경의 도움 없이 쉽게 시술할 수 있는 장점이 있다. 


\section{결 과}

경피적 확장 기관절개술은 기존의 관혈적 기관절개술에 비해 쉽고 빠르게 시행할 수 있고, 출혈이 적으며, 시술 후 감 염이 적은 장점이 있다. ${ }^{5)}$ 시술은 비교적 쉽고 간단하지만, 해 부학적으로 시술이 적합한 환자를 잘 선택하여 시행하는 것 이 필요하다. 또한 기관을 노출시켜 직접 확인하지 않은 채 기관 천자를 통해 기관공을 만들기 때문에 정확한 위치에 천 자하는 것이 중요하며, 이를 위해 기관지경의 도움을 받을 수 있다. 이비인후과 의사로서 기존의 관혈적 기관절개술을 점 차 대체해 가는 새로운 술식을 익히고 시행할 줄 알아야 기 관절개술 전문가로서의 주도권을 잃지 않을 것이다.

\section{Supplementary Video Legend}

Video 1. Percutaneous dilatational tracheostomy using Ciaglia Blue Rhino Percutaneous Dilatational Tracheostomy Kit ${ }^{\circledR}$.

\section{Supplementary Materials}

The Data Supplement is available with this article at https://doi. org/10.3342/kjorl-hns.2021.00948.

\section{Acknowledgments}

This research was supported by Basic Science Research Program through the National Research Foundation of Korea (NRF) funded by the Ministry of Education(2021R1I1A4A01059504).

\section{Author Contribution}

Conceptualization: Inn Chul Nam. Methodology: Kwi Ju Yu. Resources: Seulah Lee. Writing — original draft: So Yun Lim. Writing — review \& editing: Inn Chul Nam.

\section{ORCID}

Inn Chul Nam

https://orcid.org/0000-0001-9246-1047

\section{REFERENCES}

1) Ciaglia P, Firsching R, Syniec C. Elective percutaneous dilatational tracheostomy. A new simple bedside procedure; preliminary report. Chest 1985;87(6):715-9.

2) Friedman Y, Fildes J, Mizock B, Samuel J, Patel S, Appavu S, et al. Comparison of percutaneous and surgical tracheostomies. Chest
1996;110(2):480-5.

3) Simpson TP, Day CJ, Jewkes CF, Manara AR. The impact of percutaneous tracheostomy on intensive care unit practice and training. Anaesthesia 1999;54(2):186-9.

4) Toursarkissian B, Zweng TN, Kearney PA, Pofahl WE, Johnson SB, Barker DE. Percutaneous dilational tracheostomy: Report of 141 cases. Ann Thorac Surg 1994;57(4):862-7.

5) Freeman BD, Isabella K, Lin N, Buchman TG. A meta-analysis of prospective trials comparing percutaneous and surgical tracheostomy in critically ill patients. Chest 2000;118(5):1412-8.

6) Susarla SM, Peacock ZS, Alam HB. Percutaneous dilatational tracheostomy: Review of technique and evidence for its use. J Oral Maxillofac Surg 2012;70(1):74-82.

7) Mehta C, Mehta Y. Percutaneous tracheostomy. Ann Card Anaesth 2017;20(5):S19-25.

8) Disayabutr S, Tscheikuna J, Tangsujaritvijit V, Nana A. Experience of percutaneous dilatational tracheostomy by using Grigg's technique in Siriraj hospital. J Med Assoc Thai 2013;96 Suppl 2: S22-8.

9) Sarani B, Kinkle W, Reilly P. Pitfalls in percutaneous dilational tracheostomy using the Ciaglia one-step technique. South Med J 2008;101(3):297-302.

10) Terrani A, Bassi E, Valcarenghi C, Charbonney E, Ouellet $P$, Gosselin $\mathrm{P}$, et al. Translaryngeal tracheostomy needle introducer: A simple device to improve safety and reduce complications during Fantoni's translaryngeal tracheostomy procedure: Trial on human cadavers. Intensive Care Med Exp 2019;7(1):9.

11) Giri PC, Bellinghausen Stewart A, Dinh VA, Chrissian AA, Nguyen HB. Developing a percutaneous dilatational tracheostomy service by medical intensivists: Experience at one academic institution. J Crit Care 2015;30(2):321-6.

12) Shin HI, Jang KI, Kim KM, Nam IC. Comparison of surgical tracheostomy and percutaneous dilatational tracheostomy in intensive care unit patients. Korean J Otorhinolaryngol-Head Neck Surg 2019;62(5):288-93.

13) McCormick B, Manara AR. Mortality from percutaneous dilatational tracheostomy. A report of three cases. Anaesthesia 2005;60(5):490-5.

14) Grant CA, Dempsey G, Harrison J, Jones T. Tracheo-innominate artery fistula after percutaneous tracheostomy: Three case reports and a clinical review. Br J Anaesth 2006;96(1):127-31.

15) Ciaglia P, Graniero KD. Percutaneous dilatational tracheostomy. Results and long-term follow-up. Chest 1992;101(2):464-7.

16) Das P, Zhu H, Shah RK, Roberson DW, Berry J, Skinner ML. Tracheotomy-related catastrophic events: Results of a national survey. Laryngoscope 2012;122(1):30-7.

17) Cho YJ, Lim JH, Lee YJ, Nam IC. Severe complication of percutaneous dilatational tracheostomy. J Korean Soc Laryngol Phoniatr Logop 2016;27(1):54-7. 